\title{
Systemic Inflammatory Mediators in Post-Traumatic Complex Regional Pain Syndrome (CRPS I) - Longitudinal InVESTigations AND DifFERENCES TO CONTROL GROUPS
}

\author{
Ch. Schinkel ${ }^{1}$, A. Scherens ${ }^{2}$, M. Köller ${ }^{1}$, G. Roellecke ${ }^{1}$, G. Muhr ${ }^{1}$, C. Maier ${ }^{2}$
}

\author{
${ }^{1}$ Berufsgenossenschaftliche Kliniken Bergmannsheil, Department of Surgery, Ruhr-University, Bochum, Germany \\ ${ }^{2}$ Berufsgenossenschaftliche Kliniken Bergmannsheil, Department of Pain Therapy, Ruhr-University, Bochum, Germany
}

\begin{abstract}
Objectives: The Complex Regional Pain Syndrome I (CRPS I) is a disease that might affect an extremity after trauma or operation. The pathogenesis remains yet unclear. It has clinical signs of severe local inflammation as a result of an exaggerated inflammatory response but neurogenic dysregulation also contributes to it. Some studies investigated the role inflammatory mediators and cytokines; however, few longitudinal studies exist and control groups except healthy controls were not investigated yet.

Methods: To get further insights into the role of systemic inflammatory mediators in CRPS I, we investigated a variety of pro-, anti-, or neuro-inflammatory mediators such as C-Reactive Protein (CRP), White Blood Cell Count (WBC), Interleukins 4, 6, 8, 10, 11, 12 (p70), Interferon gamma, Tumor-Necrosis-Factor alpha (TNF- $\alpha$ ) and its soluble Receptors I/II, soluble Selectins (E,L,P), Substance-P (SP), and Calcitonin Gene-Related Peptide (CGRP) at different time points in venous blood from patients with acute (AC) and chronic (CC) CRPS I, patients with forearm fractures (FR), with neuralgia (NE), and from healthy volunteers (C).

Results: No significant changes for serum parameters investigated in CRPS compared to control groups were found except for CC/C (CGRP $p=0.007$ ), $\mathrm{FR} / \mathrm{C}(\mathrm{CGRP} \mathrm{p}=0.048)$ and AC/CC (IL-12 $\mathrm{p}=0.02$; TNFRI/II $p=0.01 ; \mathrm{SP} p=0.049)$. High interindividual variations were observed. No intra- or interindividual correlation of parameters with clinical course (e.g. chronification) or outcome was detectable.

Conclusion: Although clinically appearing as inflammation in acute stages, local rather than systemic inflammatory responses seem to be relevant in CRPS. Variable results from different studies might be explained by unpredictable intermittent release of mediators from local inflammatory processes into the blood combined with high interindividual variabilities. A clinically relevant difference to various control groups was not notable in this pilot study. Determination of systemic inflammatory parameters is not yet helpful in diagnostic and follow-up of CRPS I
\end{abstract}

Key words: CRPS-I, Reflex dystrophy, Inflammation, Cytokines

\section{INTRODUCTION}

The Complex Regional Pain Syndrome type I is a frequent complication in surgical patients after trauma or operation on an extremity. It is characterized by disproportionate pain, allodynia, vasomotor changes, decreased range of motion and edema in the affected limb [1]. Prospective studies in patients with distal radial fractures showed an incidence of CRPS I up to $20 \%[2,3]$.

Although the clinical picture and epidemiology of CRPS I are well known, the underlying pathophysiology remains unclear.

Diverse explanations exist for the pathogenesis including abnormal function of the central nervous system $[4,5]$, increased efferent sympathetic response following injury $[6,7]$, upregulated alpha-adrenoreceptors [8], oxidative stress [9], or an excessive neuro-inflammatory response $[10,11]$.

In a previous study we demonstrated that in $\mathrm{pa}-$ tients with CRPS I several changes in systemic inflammatory mediators can be noted [12]. However, in this study as in several others $[10,11,13]$, no control groups other than healthy volunteers were used. In addition no longitudinal investigations exist for systemic inflammatory parameters.

Thus the objective of our study was to further elucidate whether inflammatory mediators are involved in the pathogenesis of CRPS I by multidirectional analysis of inflammatory and neuro-inflammatory mediators in plasma of patients presenting signs of acute or chronic CRPS I compared to healthy controls, patients with neuralgia, or forearm fractures in a longitudinal manner.

\section{Materials AND Methods}

Twenty-two patients (15 females and 7 males) with a mean age of 47 years (range 29-82 years) with clinically diagnosed acute or chronic CRPS I of an upper limb were examined between May 2003 and May 2004 at the Division of Paintherapy, Department of Anesthesiology, and the Department of Surgery, University Hospital Bergmannsheil, Ruhr-University, Bochum, Germany. Within this group 12 patients presented with a chronic form (6 female, 6 male, 47 yrs. (29-82 yrs.)) and 10 patients with acute forms ( 9 female, 1 
Table 1. Groups investigated.

\begin{tabular}{l|l|l|l|l}
\hline $\begin{array}{l}\text { Acute CRPS I } \\
(\mathrm{AC})\end{array}$ & $\begin{array}{l}\text { Chronic CRPS I } \\
(\mathrm{CC})\end{array}$ & $\begin{array}{l}\text { Neuralgia } \\
(\mathrm{NE})\end{array}$ & $\begin{array}{l}\text { Fracture } \\
(\mathrm{FR})\end{array}$ & $\begin{array}{l}\text { Healthy controls } \\
(\mathrm{C})\end{array}$ \\
\hline clinical criteria of IASP & clinical criteria of IASP & $\begin{array}{l}\text { injury of peripheral } \\
\text { nerves with persisting } \\
\text { pain }\end{array}$ & $\begin{array}{l}\text { hand-/ distal forearm } \\
\text { fractures }\end{array}$ & \\
\hline acute stage; $<6$ months & $>6$ and $<12$ months & & $5-6$ weeks after injury & \\
\hline
\end{tabular}

Table 2. Parameters investigated.

\begin{tabular}{l|l|l}
\hline Cytokines and Receptors & Neuropeptides & Soluble Selectins \\
\hline Interleukin 4 (IL-4) & Substance P (SP) & Soluble E-Selectin (sE-Selectin) \\
\hline IL-6 & $\begin{array}{l}\text { Calcitonin Gene-Related- } \\
\text { Peptide (CGRP) }\end{array}$ & sL-Selectin \\
\hline IL-8 & & sP-Selectin \\
\hline IL-10 & & \\
\hline IL-11 & & \\
\hline IL-12(p70) & & \\
\hline $\begin{array}{l}\text { Tumor Necrosis Factor } \\
\text { alpha (TNF- } \alpha \text { ) }\end{array}$ & & \\
\hline $\begin{array}{l}\text { Soluble TNF Receptor I } \\
\text { and II (sTNFRI/II) }\end{array}$ & & \\
\hline \begin{tabular}{l} 
Interferon gamma (IFN- $\gamma$ ) \\
\hline
\end{tabular} & & \\
\hline
\end{tabular}

Table 3. Time points of investigations.

\begin{tabular}{l|l|l|l|l}
\hline Acute CRPS I & Chronic CRPS I & Neuralgia & Fracture & Healthy controls \\
\hline week 0,1,2, 4, 6, 12 & week 0,12,24 & week 1-6 & week 5-6 after trauma & week 1 \\
\hline
\end{tabular}

male, 46 yrs. (29-69 yrs.)). As control groups 8 healthy volunteers (4 female, 4 male, 41 yrs. (25-52 yrs.)), 5 patients with forearm fractures ( 1 female, 4 male, 48 yrs. (18-78 yrs.)), and 4 patients with neuralgia (1 female, 3 male, 31-61 yrs.)) were included.

The diagnosis of CRPS I was established using the criteria of the 1993 Consensus Conference of the International Association for the study of Pain [1] as well as the advanced differentiating criteria published by Brühl et al. [14].

All but one patient in each CRPS I group presented with a positive bone scintigraphy.

The groups investigated were prospectively defined (Table 1).

In all patients with CRPS I, the disease was triggered by an operation or injury of the hand or wrist. 20 patients were initially treated because of fracture or soft tissue trauma at the hand or wrist. Other causes for similar clinical signs other than CRPS were excluded such as evidence of infection or delayed bone healing.

All patients were detected during follow-up visits after trauma or operation or were transferred from other hospitals. Patients with evidence of CRPS I were diagnosed and treated by an interdisciplinary group of surgeons, neurologists, physiotherapists, and anesthesiologists.

None of the patients and controls had any evidence of other inflammatory diseases or immunosuppres- sion. Diabetes, arteriosclerosis, Raynaud syndrome, smoker (>20 cigarettes/day), or peripheral polyneuropathy were also exclusion criteria.

All patients received standardized pain management (World Health Organization (WHO) protocols I/II) consisting of non-steroidal anti-inflammatory drugs, metamizol, or opiates according to their pain levels.

Informed consent was obtained from the patients and the study was approved by the ethical committee of the medical school of the Ruhr-University Bochum.

The clinical monitoring consisted in a standardized past medical history questionnaire (DGSS Questionnaire), clinical evaluation and a minimum follow-up of 6 months.

After clinical examinations venous blood was drawn from the affected arm by puncture of ante-cubital vein with standard cannulas without application of a tourniquet.

White blood cell counts and C-Reactive Protein measurements were performed in the clinical routine laboratory of the hospital. Five milliliters EDTA blood were centrifuged at 3000 RPM for 10 minutes and aliquots of plasma supernatants were stored at $-80^{\circ} \mathrm{C}$.

The following parameters (Table 2) were determined in plasma samples at certain time points (Table 3) using ELISA techniques with commercial kits from R\&D Systems (Wiesbaden, Germany) according to the manufacturer protocol. 


\section{STATISTICAL ANALYSIS}

Since normality testing failed using the KolmogorovSmirnov test, the non-parametric Mann-Whitney-UTest was used to compare plasma samples of the patients with those of the control groups. Data are shown as median and range. A p-value $<0.05$ was accepted to be significant $(*)$.

\section{RESULTS}

\section{Interleukin 4:}

IL-4 was $17.2 \mathrm{pg} / \mathrm{ml}(6-87 \mathrm{pg} / \mathrm{ml})$ in healthy volunteers. There were no significant differences to AC $(18.0 \mathrm{pg} / \mathrm{ml}(0-376 \mathrm{pg} / \mathrm{ml}))$, CC $(25.4 \mathrm{pg} / \mathrm{ml}(8-91$ $\mathrm{pg} / \mathrm{ml})), \mathrm{NE}(17.9 \mathrm{pg} / \mathrm{ml}(12-44 \mathrm{pg} / \mathrm{ml})$, or FR $(25.8$ $\mathrm{pg} / \mathrm{ml}(13-54 \mathrm{pg} / \mathrm{ml}))$. There was no detectable trend within the clinical course of AC or CC but high intraand interindividual variations were observed.

\section{Interleukin 6:}

All groups investigated remained close to the control median of $9.5 \mathrm{pg} / \mathrm{ml}(8-184 \mathrm{pg} / \mathrm{ml}))$. AC: $9 \mathrm{pg} / \mathrm{ml}(2-$ $190 \mathrm{pg} / \mathrm{ml}) ; \mathrm{CC}: 10 \mathrm{pg} / \mathrm{ml}(3-46 \mathrm{pg} / \mathrm{ml})) ; \mathrm{NE}: 12$ $\mathrm{pg} / \mathrm{ml}(10-16 \mathrm{pg} / \mathrm{ml})$; FR: $9 \mathrm{pg} / \mathrm{ml}(8-19 \mathrm{pg} / \mathrm{ml}))$. No trend was seen within group AC or CC.

\section{Interleukin 8:}

IL-8 was not detectable in most samples. In group $C$ and FR it was never detected $(0 \mathrm{pg} / \mathrm{ml})$, in $\mathrm{AC} 1 \mathrm{pg} / \mathrm{ml}$ $(0-6 \mathrm{pg} / \mathrm{ml})$, in CC $0 \mathrm{pg} / \mathrm{ml}(0-9 \mathrm{pg} / \mathrm{ml})$, and in NE 0 $\mathrm{pg} / \mathrm{ml}(0-1 \mathrm{pg} / \mathrm{ml})$.

\section{Interleukin 10:}

IL-10 was elevated in group FR compared to C (16.1 $\mathrm{pg} / \mathrm{ml}(9-17 \mathrm{pg} / \mathrm{ml})$ vs. $4.0 \mathrm{pg} / \mathrm{ml}(1-60 \mathrm{pg} / \mathrm{ml}))$ but the difference was not significant. Group AC (5.5 $\mathrm{pg} / \mathrm{ml}(0-246 \mathrm{pg} / \mathrm{ml}), \mathrm{CC}(7.6 \mathrm{pg} / \mathrm{ml}(0-36 \mathrm{pg} / \mathrm{ml}))$, and $\mathrm{NE}(7.7 \mathrm{pg} / \mathrm{ml}(2-248 \mathrm{pg} / \mathrm{ml}))$ remained in between. High interindividual variations were shown but there was no trend over time.

\section{Interleukin 11:}

Whereas AC, CC, and FR remained for median and range almost identical with $C(0.5 \mathrm{pg} / \mathrm{ml}(0-74 \mathrm{pg} / \mathrm{ml})$, patients from group NE showed higher values (26.1 $\mathrm{pg} / \mathrm{ml}(0-211 \mathrm{pg} / \mathrm{ml})$. However, this trend was not significant due to high interindividual variations.

Interleukin 12 ( $p 70)$ :

Despite the fact that all groups showed a median of only 0 to $1 \mathrm{pg} / \mathrm{ml}$, groups AC (1 pg/ml (0-352 $\mathrm{pg} / \mathrm{ml}))$ versus CC $(0 \mathrm{pg} / \mathrm{ml}(0-141 \mathrm{pg} / \mathrm{ml}))$ were significantly different $(\mathrm{p}=0.02)$ but only if all different time points were added and in no case for a single individual. IL-12 (p70) was never detected in group FR. Group C (1 pg/ml (0-33 pg/ml)) was not different to patients. No relevant changes over time were demonstrable.

\section{Tumor Necrosis Factors alpha:}

TNF plasma levels remained close to $C$ values (12 $\mathrm{pg} / \mathrm{ml}(4-69 \mathrm{pg} / \mathrm{ml})$ ) without any trend over time or within the different groups.
Interferon gamma:

All patient groups showed lower values than healthy controls (C: $11.4 \mathrm{pg} / \mathrm{ml}(0-570 \mathrm{pg} / \mathrm{ml})$; AC $7.0 \mathrm{pg} / \mathrm{ml}$ (0-1946 pg/ml); CC $0.4 \mathrm{pg} / \mathrm{ml}(0-2982 \mathrm{pg} / \mathrm{ml}) ; \mathrm{NE}$ (2.1 pg/ml (0-143 pg/ml); FR $0.6 \mathrm{pg} / \mathrm{ml}(0-4254$ $\mathrm{pg} / \mathrm{ml})$ ), but these differences did not reach significance due to very high interindividual variations. No correlation with clinical course was found for AC or CC.

\section{Soluble Selectins:}

All three groups of soluble selectine (sE, sP, sL) remained very close to healthy controls (sE: $1.9 \mathrm{pg} / \mathrm{ml}$ (1.1-54 pg/ml); sP: $0.8 \mathrm{pg} / \mathrm{ml}(0.7-1.1 \mathrm{pg} / \mathrm{ml})$; sL: $23.3 \mathrm{pg} / \mathrm{ml}(19.5-24.6 \mathrm{pg} / \mathrm{ml})$ without high interindividual variations or changes over the observation period.

Soluble TNF Receptors I/II:

For both receptors all groups remained close to C (I: $87 \mathrm{pg} / \mathrm{ml}$ (63-105 pg/ml); II: $343 \mathrm{pg} / \mathrm{ml}$ (312-340 $\mathrm{pg} / \mathrm{ml})$. Despite this fact a significant difference was calculated between AC and CC (I: $85 \mathrm{pg} / \mathrm{ml}$ (62-129 $\mathrm{pg} / \mathrm{ml})$ vs. $73 \mathrm{pg} / \mathrm{ml}(40-132 \mathrm{pg} / \mathrm{ml}) ;$ II: $377 \mathrm{pg} / \mathrm{ml}$ (264-497 pg/ml) vs. $322 \mathrm{pg} / \mathrm{ml}(152-463 \mathrm{pg} / \mathrm{ml}) ; \mathrm{p}=$ 0.01) for all values taken together but not for individual patients or different time points. No relevant changes over the time course were seen.

\section{Substance P:}

All groups showed higher levels of sP compared to C (35 pg/ml (1-72 pg/ml) with a maximum in $\mathrm{NE}$ patients (69 $\mathrm{pg} / \mathrm{ml}(4-87 \mathrm{pg} / \mathrm{ml})$ ) without reaching statistical significance. In contrast AC versus CC was significant when all days were combined (43.4 $\mathrm{pg} / \mathrm{ml}(0-67 \mathrm{pg} / \mathrm{ml})$ vs. $48.3 \mathrm{pg} / \mathrm{ml}(1-490$ $\mathrm{pg} / \mathrm{ml}) ; \mathrm{p}=0.049)$ but with broad interindividual variations and without any relevant changes over time (Fig. 1).

\section{Acute/chronic: SP}

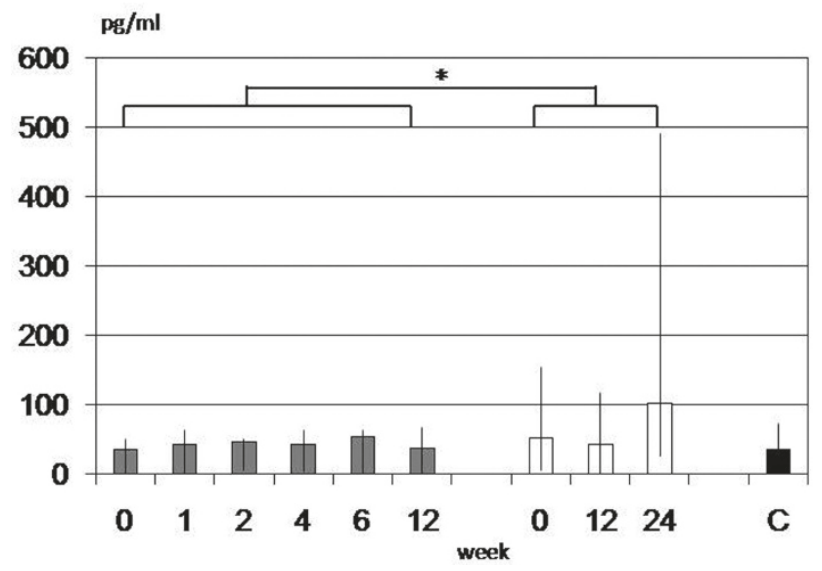

Fig. 1. In acute CRPS I (AC; grey bars) Substance P was significant lower than in chronic forms (CC, white bars) but not than healthy controls (C). A significance was reached only when all days were combined $(\mathrm{p}=0.049)$. High interindividual variations are shown and no relevant changes over time were observed. 
Calcitonin-Gene-Related-Peptide:

Finally CGRP revealed some significant differences between $\mathrm{C}(15.5 \mathrm{pg} / \mathrm{ml}(9-21 \mathrm{pg} / \mathrm{ml}))$ and FR (6.0 $\mathrm{pg} / \mathrm{ml}(3-16 \mathrm{pg} / \mathrm{ml}) ; \mathrm{p}=0.048)$ or CC $(6.5 \mathrm{pg} / \mathrm{ml}(2-$ $32 \mathrm{pg} / \mathrm{ml}) ; \mathrm{p}=0.007)$ but also for week 12 and 24 alone $(p<0.05)$. A high interindividual variation was seen for AC with $13 \mathrm{pg} / \mathrm{ml}(2-590 \mathrm{pg} / \mathrm{ml})$. No correlation was found for clinical course and CGRP (Fig. 2).

\section{Chronic/fracture: CGRP}

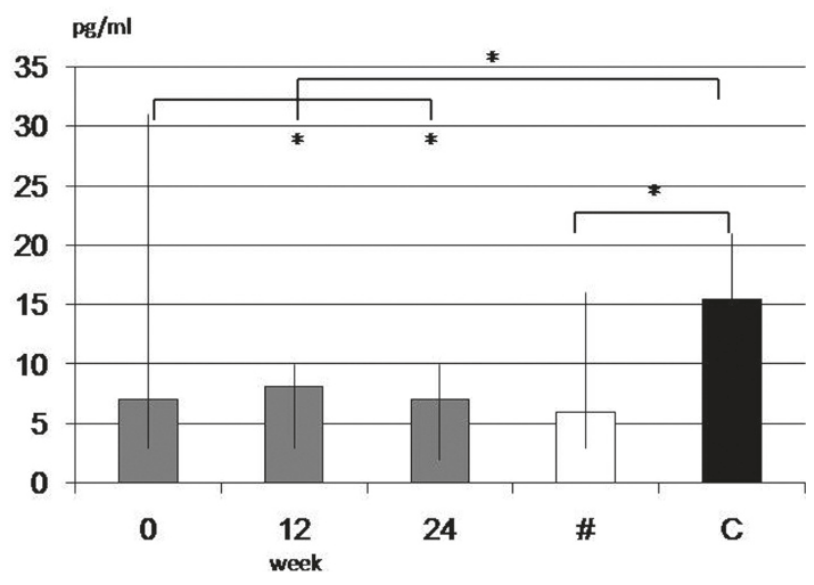

Fig. 2. Calcitonin-Gene-Related-Peptide revealed significant differences between Controls (C) and Fractures (FR) or overall chronic CRPS $(\mathrm{CC})(\mathrm{p}=0.007)$ but also for week 12 and 24 in group $\mathrm{CC}$ alone $(\mathrm{p}<0.05)$. A high interindividual variation was demonstrated. No trend was observed during clinical course.

White blood cell counts and C-Reactive Protein: All groups remained within the normal value range of 4-11 G/1 for WBC counts and below $1.2 \mathrm{mg} / \mathrm{dl}$ for CRP. No relevant trends were found.

\section{Discussion}

The clinical picture and epidemiology of Complex regional pain syndromes (CRPS, formerly reflex sympathetic dystrophy and causalgia) are well known but the underlying pathophysiology remains unclear.

CRPS is characterized by neuropathic pain in one extremity after a trauma. The initiating trauma affects primarily the extremity, but can also be a central lesion (e.g., spinal cord injury, stroke). CRPS is characterized by sensory, autonomic and motor disturbances.

Pathophysiologically there are functional changes within the central nervous system and involvement of peripheral inflammatory processes. The sympathetic nervous system plays a key role in maintaining pain and autonomic dysfunction in the affected extremity. $[6,15]$ After a primary central lesion, secondary peripheral changes in the paretic extremity are suggested to be important in initiating CRPS $[4,5]$.

Most physicians believe this syndrome is initiated by a hyperactive sympathetic system. However, various studies question this mechanism $[11,16,17]$.

From a surgeons view point the affected limb in the acute stage of CRPS I looks inflamed, is edematous, pinkish-blue or red, and warm. It has impaired function. In contrast to generalized inflammation such as SIRS or sepsis, patients with CRPS I are in good general health without malaise. In 1942 the German surgeon Paul Sudeck was the first to hypothesize that a regional inflammatory response to injury might be the cause of this syndrome (Sudeck's Atrophy) [18].

It was shown previously that macro- and microcirculatory changes in the CRPS I affected arm resemble the systemic changes in patients with SIRS or sepsis $[19,20,21]$. Those findings suggest that the profound changes in both macro- and microvascular perfusion in the CRPS I affected arm contribute to edema formation and support the hypothesis of an inflammatory associated pathogenesis of CRPS. Several small studies suggest possible efficacy of antiinflammatories for some of the symptoms of CRPS I [9, 22].

Supporting the theory of a localized inflammatory process white blood cell counts, CRP and IL-6 were not altered in the affected arm or in controls. The liver as the major source of IL- 6 and CRP and the central immune organ in systemic inflammatory responses does not seem to be involved in this disease.

In contrast to our previous study in acute CRPS I with single time point investigation we could find only distinct elevations of sP and TNFRI/II again, but not of IL-8. The suppression of soluble selectins was not shown again in this study [12].

Calcitonin Gene-Related Peptide was not altered in our previous study but this recent study has demonstrated some significant differences for CGRP such as between controls and patients after fractures or with chronic CRPS I. However those changes were marginal.

Another study in 61 patients with reflex dystrophy demonstrated also a significant induction of systemic CGRP and bradykinin levels. The authors speculate that these mediators contribute to hyperalgesia, inflammation and motor alterations in these patients [23].

Uceyler and colleagues have recently published a study with 40 patients where elevated TNF- $\alpha$ plasma levels and increased IL-2 messenger ribosomal nuclear acid (mRNA) values were found. Anti-inflammatory cytokine mRNA such as IL-4 or IL-10 were significantly suppressed [13].

In contrast, various trials have found no systemic involvement. Increased serum levels might be due to an inconsistent spill over from the local inflammatory focus $[24,25,26]$ and might explain controversial data from Huygen et al. [27] who could not demonstrate changes of IL-6, IL-1 $\beta$, TNF-alpha, Neuropeptide Y (NPY), and CRGP in serum during intermediate or acute forms of CRPS I.

Van de Beek et al. also found no difference in several cytokines (IL-1b, IL-6, IL-8, TNF- $\alpha$, IL-1ra, IL10) between CRPS I patients and healthy controls in a study where the mean duration of the disease was 10 years [28]. It is likely that patients with long lasting CRPS I develop central mechanisms that lead to the chronification at least of the sensory symptoms rather than a persistent inflammation [29]. 
Up to now the results on systemic inflammatory cytokine responses are very inconsistent and vary between the different study populations and settings. High intra- and interindividual variations were shown in our studies. There is no clinical relevance proven so far that measurement of plasma cytokines is helpful in diagnostic or follow-up of patients with CRPS I.

The cause for the different results for the neuroinflammatory mediators remains unclear too. Different definitions and terminology of the syndrome in combination with different states of disease (chronic versus acute) and time points investigated might explain these divergences.

Weber et al. have shown that in CRPS I patients a severe plasma protein extravasation after strong transcutaneous electrical stimulation and this reaction could also be induced by the application of exogenous Substance P [30].

Gradl and colleagues have recently published data from an interventional animal model in which continuous intra-arterial application of SP induced signs and symptoms of CRPS such as edema, inflammation and pain in rats. Under fluorescence microscopy enhanced leukocyte-endothelial interaction was shown but no increase in apoptosis.

This study indicates that SP is responsible for neurogenic inflammation resulting in CRPS I-like symptoms even if some clinical signs such as thermal allodynia were not present [31].

Those data are important to further elucidate the mechanisms involved and might be the fundament for further treatment studies. However, further studies might elucidate their role in the pathophysiology of CRPS I. Any clinical use cannot yet be recommended.

In contrast determination of cytokines in local artificial suction blisters on the affected arm of patients with acute CRPS I seem to result in more consistent data such as high levels of IL-6 and TNF [27], supporting the theory that CRPS I is associated with a local inflammatory pathogenesis.

Munnikes and Groeneweg from the group of Huygen have published recently two studies on inflammatory mediators in artificial suction blisters in intermediate stages of CRPS I [32, 33]. Again IL-6 and TNF$\alpha$ were significantly increased in the suction blisters on the affected site despite significant improvement of symptoms and pain compared to the acute stage. The persistence of high inflammatory mediators locally excludes the use of cytokine monitoring for follow-up at the recent time. However, involvement of inflammatory mediators, vasoactive substances such as Endothelin-1 or Nitric oxide seem to be proven now in various study settings.

In another study of this group using again their suction blister model they found 10 representative cytokines out of 25 investigated using a multiplex bead array assay [34].

Further studies that will include control groups such as patients with fracture or with neuropathic pain have to elucidate more precise inflammatory mediator profiles to differentiate those various forms of acute or chronic local inflammation.

\section{CONCLUSION}

Acute forms of Complex Regional Pain Syndrome I show clinically signs of inflammation. The pathogenesis is still not clear.

Recent studies have proven local involvement of inflammatory mediators, where as systemic responses are very inconsistent which might be due to irregular occurring systemic overspill of local mediators. A clear correlation between acute or chronic stages of disease and systemic inflammatory mediators is not yet shown. This holds true especially if those groups are compared to healthy controls, patients with forearm fractures or neuralgia.

Further studies on local inflammatory responses will elucidate the role of inflammatory components in the pathogenesis of CRPS I. Additional larger longitudinal studies in patients and relevant control groups are warranted before any clinical use for diagnostics or follow-up can be recommended.

\section{REFERENCES}

1. Stanton-Hicks M, Janig W, Hassenbusch S, Haddox JD, Boas R, Wilson P. Reflex sympathetic dystrophy: changing concepts and taxonomy. Pain 1995;63(1):127-33.

2. Atkins RM, Duckworth T, Kanis JA. Features of algodystrophy after Colles' fracture. J Bone Joint Surg Br 1990; 72(1):105-10.

3. Field J, Atkins RM. Algodystrophy is an early complication of Colles' fracture. What are the implications? J Hand Surg [Br] 1997;22(2):178-82.

4. Rowbotham MC, Twilling L, Davies PS, et al. Oral opioid therapy for chronic peripheral and central neuropathic pain Advances in neuropathic pain: diagnosis, mechanisms, and treatment recommendations [Recent trends in understanding and therapy of complex regional pain syndromes] Complex regional pain syndrome--diagnostic, mechanisms, CNS involvement and therapy. $\mathrm{N}$ Engl J Med 2003;348(13):1223-32.

5. Dworkin RH, Backonja M, Rowbotham MC, et al. Advances in neuropathic pain: diagnosis, mechanisms, and treatment recommendations. Arch Neurol 2003;60(11): 1524-34.

6. Chelimsky TC, Low PA, Naessens JM, Wilson PR, Amadio PC, O'Brien PC. Value of autonomic testing in reflex sympathetic dystrophy. Mayo Clin Proc 1995;70(11):102940.

7. AbuRahma AF, Robinson PA, Powell M, Bastug D, Boland JP. Sympathectomy for reflex sympathetic dystrophy: factors affecting outcome. Ann Vasc Surg 1994;8(4): 372-9.

8. Arnold JM, Teasell RW, MacLeod AP, Brown JE, Carruthers SG. Increased venous alpha-adrenoceptor responsiveness in patients with reflex sympathetic dystrophy. Ann Intern Med 1993;118(8):619-21.

9. Goris RJ, Dongen LM, Winters HA. Are toxic oxygen radicals involved in the pathogenesis of reflex sympathetic dystrophy? Free Radic Res Commun 1987;3(1-5): $13-8$.

10. Oyen WJ, Arntz IE, Claessens RM, van der Meer JW, Corstens FH, Goris RJ. Reflex sympathetic dystrophy of the hand: an excessive inflammatory response? Pain 1993; 55(2):151-7.

11. Drummond PD, Finch PM, Edvinsson L, Goadsby PJ. Plasma neuropeptide $\mathrm{Y}$ in the symptomatic limb of $\mathrm{pa}$ tients with causalgic pain. Clin Auton Res 1994;4(3): 113-6. 
12. Schinkel C, Gaertner A, Zaspel J, Zedler S, Faist E, Schuermann M. Inflammatory mediators are altered in the acute phase of posttraumatic complex regional pain syndrome. Clin J Pain. 2006;22(3):235-9.

13. Uçeyler N, Eberle T, Rolke R, Birklein F, Sommer C. Differential expression patterns of cytokines in complex regional pain syndrome. Pain [serial on the Internet] 2007;132(1-2):195-205. Internet: doi:10.1016/j.pain.2007. 07.031 .

14. Bruehl S, Harden RN, Galer BS, et al. External validation of IASP diagnostic criteria for Complex Regional Pain Syndrome and proposed research diagnostic criteria. International Association for the Study of Pain. Pain 1999; 81(1-2):147-54.

15. Bonica J. Causalgia and other reflex sympathetic dystrophies. In: Bonica J, Liebeskind J, Albe-Fessard D, editors. Advances in Pain Research and Therapy. New York: Raven press. p. 141-66.

16. Harden RN, Duc TA, Williams TR, Coley D, Cate JC, Gracely RH. Norepinephrine and epinephrine levels in affected versus unaffected limbs in sympathetically maintained pain. Clin J Pain 1994;10(4):324-30.

17. Blanchard J, Ramamurthy S, Walsh N, Hoffman J, Schoenfeld L. Intravenous regional sympatholysis: a double-blind comparison of guanethidine, reserpine, and normal saline. J Pain Symptom Manage 1990;5(6):357-61.

18. Sudeck P. The so called acute bone atrophy als an inflammatory process. Chirurg 1942;14:449-58.

19. van der Laan L, Goris RJ. Reflex sympathetic dystrophy. An exaggerated regional inflammatory response? Hand Clin 1997;13(3):373-85.

20. Schurmann M, Gradl G, Wizgal I, Tutic M, Moser C, Azad S, Beyer A. Clinical and physiologic evaluation of stellate ganglion blockade for complex regional pain syndrome type I. Clin J Pain 2001;17(1):94-100.

21. Goris RJ. Reflex sympathetic dystrophy: model of a severe regional inflammatory response syndrome. World J Surg 1998;22(2):197-202.

22. Christensen K, Jensen EM, Noer I. The reflex dystrophy syndrome response to treatment with systemic corticosteroids. Acta Chir Scand 1982;148(8):653-5.

23. Blair SJ, Chinthagada M, Hoppenstehdt D, Kijowski R, Fareed J. Role of neuropeptides in pathogenesis of reflex sympathetic dystrophy. Acta Orthop Belg 1999;64(4): 448-51.

24. Baggiolini M, Moser B, Clark-Lewis I. Interleukin-8 and related chemotactic cytokines. The Giles Filley Lecture. Chest 1994;105(3 Suppl):95S-98S.

25. Lin RY, Astiz ME, Saxon JC, Saha DC, Rackow EC. Relationships between plasma cytokine concentrations and leukocyte functional antigen expression in patients with sepsis. Crit Care Med 1994;22(10):1595-602.

26. van Zee KJ, DeForge LE, Fischer E, et al. IL-8 in septic shock, endotoxemia, and after IL-1 administration. J Immunol 1991;146(10):3478-82.
27. Huygen F, Bruijn A de, Bruijn M de, Groeneweg J, Klein $\mathrm{J}$, Zijistra F. Evidence for local inflammation in complex regional pain syndrome type 1. Mediators Inflamm 2002; 11(1):47-51.

28. van Beek WJ de, Remarque EJ, Westendorp RG, van Hilten JJ. Innate cytokine profile in patients with complex regional pain syndrome is normal. Pain 2001;91(3):25961.

29. Rommel O, Malin JP, Zenz M, Janig W. Quantitative sensory testing, neurophysiological and psychological examination in patients with complex regional pain syndrome and hemisensory deficits. Pain 2001;93(3):279-93.

30. Weber M, Birklein F, Neundorfer B, Schmelz M. Facilitated neurogenic inflammation in complex regional pain syndrome. Pain 2001;91(3):251-7.

31. Gradl G, Finke B, Schattner S, Gierer P, Mittlmeier T, Vollmar B. Continuous intra-arterial application of substance $\mathrm{P}$ induces signs and symptoms of experimental complex regional pain syndrome (CRPS) such as edema, inflammation and mechanical pain but no thermal pain. Neuroscience [serial on the Internet] 2007;148(3):757-65. Internet: doi:10.1016/j.neuroscience.2007.06.024.

32. Munnikes RJM, Muis C, Boersma M, Heijmans-Antonissen C, Zijlstra FJ, Huygen FJPM. Intermediate stage complex regional pain syndrome type 1 is unrelated to proinflammatory cytokines. Mediators Inflamm [serial on the Internet] 2006;2005(6):366-72. Internet: doi:10.1155/MI. 2005.366 .

33. Groeneweg JG, Huygen FJPM, Heijmans-Antonissen C, Niehof S, Zijlstra FJ. Increased endothelin-1 and diminished nitric oxide levels in blister fluids of patients with intermediate cold type complex regional pain syndrome type 1. BMC Musculoskelet Disord [serial on the Internet] 2006;7:91. Internet: doi:10.1186/1471-2474-7-91.

34. Heijmans-Antonissen C, Wesseldijk F, Munnikes RJ, et al. Multiplex bead array assay for detection of 25 soluble cytokines in blister fluid of patients with complex regional pain syndrome type 1. Mediators Inflamm [serial on the Internet] 2006;2006(1):28398. Internet: doi:10.1155/MI/ $2006 / 28398$.

Received: April 7, 2008 / Accepted: June 27, 2008

Address for correspondence:

Christian Schinkel, M.D., FACS

Assoc. Prof. of Surgery

Berufsgenossenschaftliche Kliniken Bergmannsheil

Dept. of Surgery

Ruhr University Bochum

Buerkle-de-la-Camp-Pl.1

44789 Bochum

Germany

Phone: +49-234-3020

Fax: +49-234-302-6530

E-mail: christian.schinkel@ruhr-uni-bochum.de 